\title{
Early-onset non-syndromic cataract
}

INSERM

\section{Source}

INSERM. (1999). Orphanet: an online rare disease and orphan drug data base. Early-onset non-syndromic cataract. ORPHA:91492

Early-onset non-syndromic cataract is a rare, genetic, non-syndromic developmental defect of the eye disorder, with high clinical and genetic heterogeneity, most frequently characterized by bilateral, symmetrical, non-progressive cataracts which present at birth or in early-childhood. Additional ocular manifestations (e.g. anterior segment dysgenesis, colobomas, nystagmus, microcornea, microphthalmia, myopia) may be associated, however other organs/systems are usually not affected. 